\title{
Trends, challenges, and responses of a 20 -year, volunteer water monitoring program in Alabama
}

\author{
$\underline{\text { William G. Deutsch }}^{1}$ and Sergio S. Ruiz-Córdova ${ }^{1}$
}

\begin{abstract}
Volunteer water monitoring programs are one of the most popular forms of citizen science, but many face governmental funding cuts and other threats to their continuation. Alabama Water Watch (AWW) is such a program that for more than 20 years has had positive influences on ecosystems and society through environmental education, waterbody protection and restoration, and promotion of improved water policy. A temporal analysis of 15 program indicators revealed 4 phases of AWW that followed general patterns of organizational development. These included periods of rapid growth, cresting, moderate decline, and stabilization at a lower level of activity. Five factors influenced these trends: saturation of potential groups, loss of monitors from aging, disillusionment and monitor fatigue, societal change, and loss of government funding. These factors were evaluated and responses to each are described. Keys to long-term viability of AWW include consistent attention to monitors, data credibility, a user-friendly online database, volunteer trainers, a nongovernmental association, and an institutional transition resulting in funding and staff continuity.
\end{abstract}

Key Words: citizen science; community-based monitoring; program sustainability; public participation in scientific research; volunteer water monitoring

\section{INTRODUCTION}

Volunteer water monitoring programs are one of the most popular forms of citizen science and have been implemented in all but a few U.S. states (National Water Program, http://www. usawaterquality.org) and in several countries (Deutsch et al. 2010, Conrad and Hilchey 2011). A national survey characterized and assessed the needs of 94 volunteer water monitoring groups from 41 U.S. states (Green et al. 2013). The study found that most programs operated statewide, primarily with state funding, focused on monitoring rivers and streams, and indicated that funding stability was their top concern. Large volunteer monitoring programs are usually coordinated through universities (Savan et al. 2003), Cooperative Extension Systems, governmental agencies, or nonprofit organizations. Wagenet and Pfeffer (2007) found that volunteer groups that are affiliated with these programs and receive centralized support tend to outlast groups without such connections.

There is a lack of quantitative studies that document how volunteer water monitoring programs progress over the long-term or are discontinued. Although water monitoring programs are diverse in their approach and operations, all face similar challenges of recruiting and retaining volunteers, managing and using the collected information, and securing adequate funding and other resources to remain viable. New groups and programs have much to learn from veteran programs that have adequately documented their development with quantifiable indicators.

The need for understanding the sustainability of volunteer water monitoring programs is more important than ever because traditional funding sources are abruptly ending. In the early 1990s, after about 20 years of implementing the federal Clean Water Act, it was determined that the Act did much to control point source pollution from industries and municipalities, but relatively little to control urban and rural nonpoint source pollution. Several programs to increase public awareness about water and nonpoint source pollution abatement were subsequently initiated via federal grants from the U.S Environmental Protection Agency (EPA) and the U.S. Department of Agriculture (USDA). In particular, many volunteer water monitoring programs were begun with funding from EPA (Clean Water Act Section 319 grants; Kerr et al. 1994), and a National Facilitation Project in Volunteer Water Monitoring was begun through the Collaborative Research, Education and Extension System, and later the National Institute of Food and Agriculture, of USDA. Both EPA and USDA funding for water monitoring programs has been severely cut in recent years, and the viability of several statewide, regional, and national programs is threatened.

Alabama Water Watch (AWW) is a citizen volunteer water monitoring and watershed stewardship program that began in 1992. The mission of AWW is to educate citizens about water issues in Alabama and the world, and how to use standardized equipment and techniques to gather credible water information. Citizens then make positive impacts on ecosystems and society by using their water data for environmental education, waterbody restoration and protection, and advocacy for improved water quality and policy (Deutsch 2013; Alabama Water Watch, http:// www.alabamawaterwatch.org).

AWW has two major components, a university-based program and a nongovernmental organization called the Alabama Water Watch Association (AWWA). For most of its history, the AWW program was coordinated from the Auburn University (AU) School of Fisheries, Aquaculture and Aquatic Sciences, with primary funding from the Alabama Department of Environmental Management (ADEM) and EPA, Region 4 (Clean Water Act, Section 319 grant). Additional support was provided by the Alabama Agricultural Experiment Station and the Alabama Cooperative Extension System. Since 2013, AWW has been coordinated from the AU Water Resources Center, with increased support from Alabama Agricultural Experiment Station and the Alabama Cooperative Extension System. The

\footnotetext{
${ }^{1}$ Alabama Water Watch, Auburn University Water Resources Center
} 
AWWA incorporated and registered as a 501.c. 3 organization in 1994 to promote AWW's mission, provide funding for activities and supplies, and advocate improved water quality and policy.

AWW has developed a variety of training materials and sampling protocols, and an online database to store and analyze information and provide technical support to monitoring groups. Quality assurance plans covering several elements of training, monitoring, data submission, and information dissemination received EPA approval in 1994 and 2004 for water chemistry monitoring and in 1999 for bacteriological monitoring (Alabama Water Watch, http://www.alabamawaterwatch.org).

A core activity of AWW is to conduct free certification workshops for volunteers at the local level. AWW staff and certified volunteer trainers meet with 1 to 25 citizens in public meeting rooms, homes, and schools and spend 4-6 hours in presenting program goals, basic watershed science, and specifics of testing particular variables of water quality. Certified monitors then borrow or purchase standardized kits and other supplies, and monitor one or more sites at streams or lakes on a regular basis. AWW provided active monitors with free chemical reagents for test kits as an incentive to keep monitoring. All physicochemical data are collected onsite without transporting water samples or use of laboratories. Bacteriological data are obtained by collecting water samples in the field and incubating samples for about 30 hours at a home or lab. Monitors submit their water data to AWW via an online database or by mail.

After 14 years of AWW program activities, 235 participating groups were analyzed for their distribution, longevity, and socioeconomic characteristics (Deutsch et al. 2009). Nearly $90 \%$ of the groups monitored streams; these groups sampled $64 \%$ of sites and had longevity of about 2 years. Groups that monitored lakes (reservoirs) and coastal areas collectively made up 12\% of groups, and sampled $36 \%$ of sites with considerably longer average group longevity (5-7 years) than stream groups. There were significant correlations between volunteer monitoring (number of groups, sites, and data records) and levels of education, income, and population (data for 67 Alabama counties, U.S. Census Bureau, Population Division 2013), with most monitoring being done by relatively well-educated and wealthy volunteers near population centers. Participation in AWW was relatively low in resource-limited, rural areas, with the exception of areas in the northern part of the state where population density and incomes are relatively low but where there are several lakes and concerned lake groups. The study revealed the dynamism and complexities of public participation in water monitoring on a statewide scale, and provided insights for supporting volunteer groups and recruiting in areas where monitoring is traditionally less accepted (Deutsch et al. 2009). The geographical pattern of water monitoring activity in Alabama has persisted for many years, as evidenced by a current map of cumulative monitoring sites (Fig. 1).

Among the many ways that citizen volunteer water monitoring programs like AWW have been classified within the contexts of citizen science, Informal Science Education, and Public Participation in Scientific Research (Bonney et al. 2009), AWW could be described as a Collaborative Project, with elements of a Co-created Project (Shirk et al. 2012). AWW was initially designed by university scientists, primarily aquatic ecologists, but has had considerable contributions from volunteers in refining training materials and workshops, choosing monitoring sites, and interpreting, disseminating, and applying monitoring results.

Fig. 1. Map of Alabama showing major streams and reservoirs, 9 urban centers with at least 50,000 people (large grey dots; U. S. Census Bureau, Population Division 2013), and cumulative location of Alabama Water Watch monitoring sites statewide and in shared watersheds of neighboring states, Tennessee (TN), Georgia (GA), Florida (FL), and Mississippi (MS).

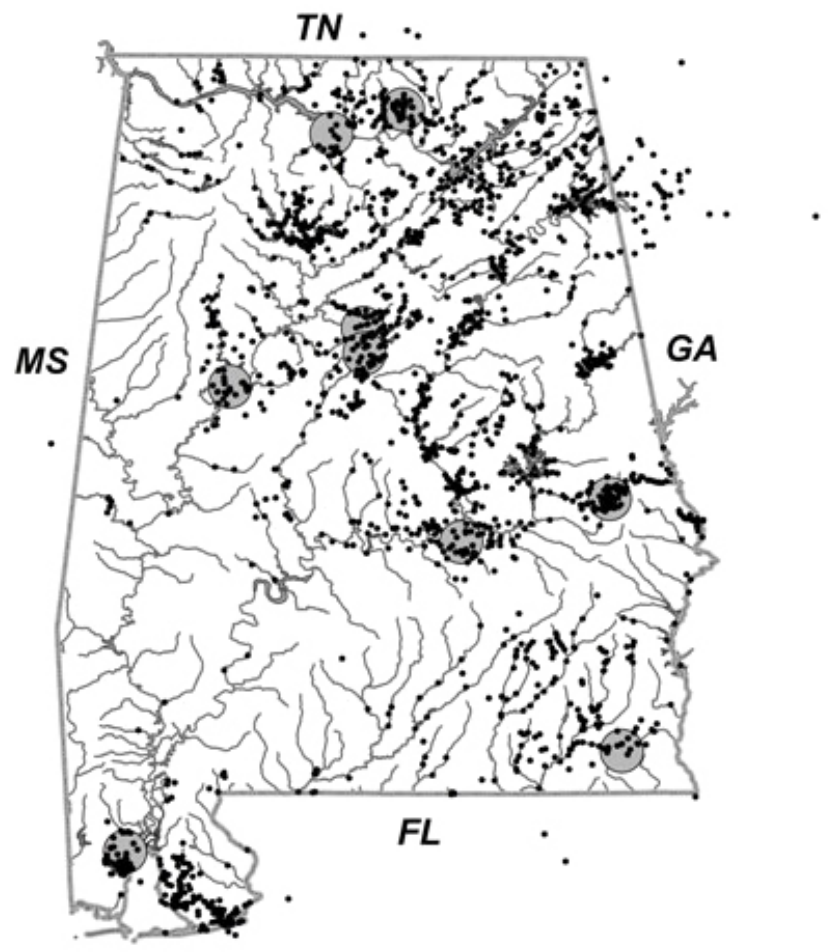

Citizen volunteer water monitoring programs may have the same basic mission of promoting public participation in the collection of scientifically valid data, but use considerably different approaches and activities. It is important to understand the goals and objectives of a program before evaluating trends and the key indicators of its success. The characteristics of AWW, including five categories with descriptions of strategies for each, are presented in Table 1.

The objective of this study was to describe AWW trends from 1993 through 2013 and relate them to factors that threaten or enhance program sustainability. Such a study would have broad implications for other citizen science programs, regardless of their objectives and approach.

\section{METHODS}

The study was based on information about monitors, groups, water data records, and other selected program indicators that had been systematically documented and obtained through queries of the MS Access 2003 database maintained by AWW. During the study period of January 1, 1993, through December 31,2013 , about 6700 individuals were certified as water monitors 
Table 1. Characteristics of Alabama Water Watch (AWW) according to five program categories and strategies, $1993-2013$.

\begin{tabular}{|c|c|}
\hline Program Category & Strategy \\
\hline \multicolumn{2}{|l|}{ Approach } \\
\hline Mission & $\begin{array}{l}\text { Raise awareness of water issues in Alabama and the world through community-based, science- } \\
\text { based collection of credible data }\end{array}$ \\
\hline Role of Volunteers & $\begin{array}{l}\text { Maximize level of citizen participation and group autonomy; citizens choose sampling sites and } \\
\text { collect, record, and own the data }\end{array}$ \\
\hline Action Strategies & $\begin{array}{l}\text { Use the approach and data for environmental education, waterbody restoration/protection, and } \\
\text { improved water policy }\end{array}$ \\
\hline \multicolumn{2}{|l|}{ Organizational Structure } \\
\hline Institutional Base & Land Grant University-coordinated program \\
\hline Program Staff & Director and coordinators for data, volunteers and outreach \\
\hline Nongovernmental Association & $\begin{array}{l}\text { Registered 501(c)(3) organization with board of directors, officers, and members to support the } \\
\text { AWW program, advance the mission, generate interest, fund-raise, and advocate water policy }\end{array}$ \\
\hline Volunteer Trainers & $\begin{array}{l}\text { Certified by program; conduct most water monitoring workshops statewide, often in partnership } \\
\text { with program staff }\end{array}$ \\
\hline \multicolumn{2}{|l|}{ Information Management } \\
\hline Quality Control & Emphasis on credible data; EPA-approved quality assurance plans \\
\hline Database & Relational database with web-based tools for storage, analyses, and retrieval of statewide data \\
\hline \multicolumn{2}{|l|}{ Public Relations } \\
\hline Interaction with Monitors & $\begin{array}{l}\text { Maximize personal contact through meetings and workshops conducted statewide at community- } \\
\text { level }\end{array}$ \\
\hline Information Dissemination & $\begin{array}{l}\text { Online data entry and public access, data interpretation sessions, user-friendly reports, blogs, } \\
\text { newsletters, toll-free office phone }\end{array}$ \\
\hline \multicolumn{2}{|r|}{ (10 } \\
\hline Program Funding & $\begin{array}{l}\text { External grants; staff support from the Alabama Agricultural Experiment Station and Alabama } \\
\text { Cooperative Extension System }\end{array}$ \\
\hline Association Funding & Foundation and nonprofit grants, membership dues, donations \\
\hline
\end{tabular}

in 1750 workshops and recertification sessions. Cumulatively, volunteer monitors collected about 75,600 data records from 2240 sites on 820 waterbodies.

Analysis of this extensive data set was primarily done through a temporal examination of program indicators, including number of monitoring groups, new group formation, group dropout, monitoring effort, and funding. Annual averages of indicators were used to describe program trends. The primary indicator chosen was the number of volunteer water monitors participating annually, followed by the number of data records submitted per year. These two indicators are central to the viability of AWW, which relies on volunteer participation and also places a premium on the collection of credible water quality data.

A monitor is defined as an individual who completed an AWW certification workshop. A monitoring group is one to several monitors who collected and submitted data from a particular site on a waterbody following AWW protocols. A site is considered active if at least one data record from it was received in a calendar year. A monitor or group is considered active if they monitored at least once in a calendar year and submitted their data to AWW. An inactive group is one that stopped submitting water data records for 12 months. When a group became active after a period of inactivity, information about its monitors and data records was included in the analyses, but it was not considered to be a new group.

Funding was based on university records of external contracts from EPA Region 4 through ADEM that were received to conduct specific AWW program activities and did not include incidental support from related projects or organizations, or university salary support. Staff time (full-time equivalents, or FTEs) was based on the annual level of direct involvement by universitybased personnel in AWW activities. Volunteer hours were based only on the time citizen volunteers spent in certification workshops and monitoring, and did not include many other activities they did in their local groups.

Patterns of change and relationships among program indicators were primarily described using the best professional judgment of experienced AWW staff. The first author was the founding cocoordinator of the program and directed AWW for 20 years. The second author was the AWW data quality coordinator for nearly 15 years. A general consensus of key factors that explained program trends was achieved through guided discussions with other program personnel with more than 25 combined years of experience in all aspects of AWW.

\section{RESULTS}

All aspects of AWW, including levels of group participation, monitoring, funding, and staff support, have been dynamic. Four relatively distinct phases of the program were identified based on temporal patterns of 15 indicators (Fig. 2). Three six-year phases were largely based on monitor activities and made comparisons of program trends more representative than comparing periods of unequal length. The fourth three-year phase was begun the year that the core government grant was discontinued (Fig. 2C) and further revealed how funding and other factors affected program sustainability. Annual averages of each indicator by phase and overall are presented in Table 2. 
Table 2. Alabama Water Watch program indicators as annual averages within each of four phases, with overall annual average, $1993-2013$.

\begin{tabular}{|c|c|c|c|c|c|c|}
\hline \multirow[b]{2}{*}{ Program Indicators } & & \multicolumn{5}{|c|}{ Annual Average } \\
\hline & & $\begin{array}{c}\text { Phase I } \\
1993-1998\end{array}$ & $\begin{array}{c}\text { Phase II } \\
1999-2004\end{array}$ & $\begin{array}{c}\text { Phase III } \\
2005-2010 \\
\end{array}$ & $\begin{array}{l}\text { Phase IV } \\
\text { 2011-2013 }\end{array}$ & $\begin{array}{c}\text { Overall } \\
1993-2013 \\
\end{array}$ \\
\hline \multirow[t]{4}{*}{ Workshops \& Monitors } & Workshops Conducted & 46 & 108 & 94 & 88 & 83 \\
\hline & Certified Monitors & 260 & 452 & 281 & 260 & 321 \\
\hline & Active Monitors & 180 & 406 & 334 & 313 & 307 \\
\hline & $\%$ Certified Active & 27 & 24 & 26 & 26 & 26 \\
\hline \multirow{4}{*}{ Monitoring Sites \& Data Records } & Active Sites & 245 & 517 & 464 & 452 & 415 \\
\hline & Data Records & 1440 & 4900 & 4340 & 3825 & 3600 \\
\hline & Records per Monitor & 7 & 12 & 13 & 12 & 11 \\
\hline & $\%$ Online Data Entry & 0 & $52^{\dagger}$ & 88 & 92 & $83^{\dagger}$ \\
\hline \multirow[t]{4}{*}{ Monitoring Groups } & New Groups & 21 & 16 & 7 & 6 & 13 \\
\hline & Active Groups & 53 & 88 & 74 & 71 & 71 \\
\hline & Inactive Groups & 8 & 19 & 13 & 8 & 13 \\
\hline & $\%$ Inactive Groups & 17 & 22 & 18 & 11 & 18 \\
\hline Government Funding & Program Funding (x \$1000) & $\$ 164$ & $\$ 200$ & $\$ 145$ & $\$ 0$ & $\$ 152$ \\
\hline \multirow{2}{*}{ Staff \& Volunteer Time } & Staff Full-Time Equivalents & 4.4 & 5.7 & 3.9 & 3.0 & 4.5 \\
\hline & Volunteer Hours & 7250 & 20,480 & 16,800 & 14,820 & 14,840 \\
\hline
\end{tabular}

Starting with the first full year of online data entry capability in 2003.

Fig. 2. Alabama Water Watch program indicators. (A) Total number of Alabama Water Watch water data records, number of volunteer monitors, and number of records per monitor; (B) Active, inactive, and new monitoring groups per year; (C) Volunteer hours, government funding, and staff time (full-time equivalents) per year over four phases (Roman numerals), 1993-2013.

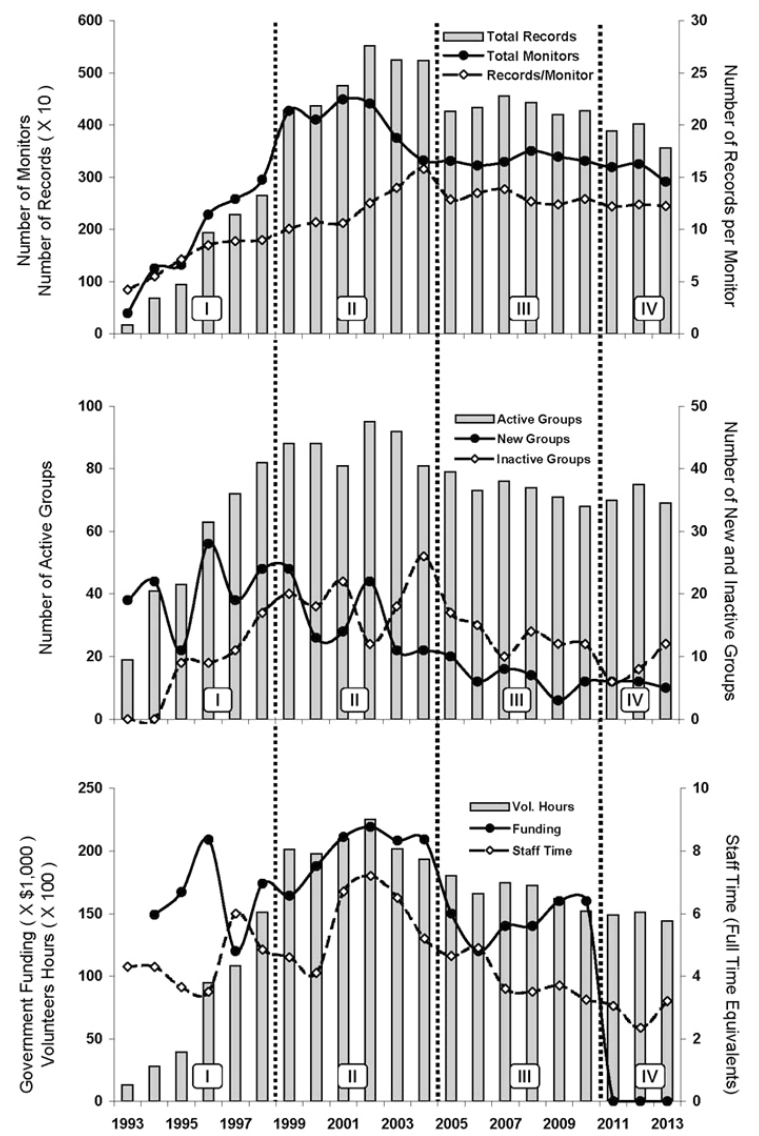

\section{Phase I: rapid expansion, 1993-1998}

The AWW program began conducting water monitoring certification workshops in early 1993. The number of workshops grew from 19 in 1993 to 100 in 1998, indicating how popular and relevant they became for a variety of community groups. This enthusiastic response from citizens was surprising to many because Alabama had recently been ranked last among U.S. states in a Green Index of Environmental Policy and Condition developed by the Institute of Southern Studies (Hall and Kerr 1991).

Because workshop demand grew at such a rapid rate, the AWW program initiated a series of Training-of-Trainers workshops in 1995 to recruit and certify volunteer trainers. Trainer candidates were active monitors who had tested water as part of AWW for at least one year and met other criteria of commitment and effectiveness, e.g., agreement to conduct at least two workshops per year. Volunteer trainers quickly became a vital part of sustaining AWW by conducting a large majority of the workshops.

An average of 260 people were certified annually in phase I (Table 2 ), and $27 \%$ of those certified became active monitors within a year. An average of 180 volunteers actively monitored each year of this period. There was more than a 7 -fold rise in the number of water monitors through phase I (Fig. 2).

The number of active monitoring sites increased rapidly each year, from 40 in 1993 to 390 in 1998. Likewise, the number of data records also sharply rose from 165 to 2646 during this phase (Fig. 2A). An average of 7 data records per monitor per year was received.

An average of 21 new monitoring groups formed each year of phase I. Some groups had previously existed but started monitoring with AWW, and other groups formed as a result of the AWW workshops. Active groups rose from 19 in 1993 to 82 in 1998. Some groups became inactive by the third year of the program, and the number of dropout groups increased from 9 in 1995 to 17 in 1998 (Fig. 2B). 
The EPA grant that primarily funded the AWW program averaged $\$ 164,000$ per year (Fig. 2C). About $75 \%$ of the grant was used to pay all staff salaries and wages allocated to AWW activities. FTEs averaged 4.4 and ranged from about 3 to 6 people during this period. Volunteer hours of monitors rose sharply throughout phase I and in 1998 exceeded 15,000 hours for training and monitoring.

\section{Phase II: cresting and realignment, 1999-2004}

In phase II, all major indicators of program size reached their apex. The number of data records submitted was highest in 2002 at 5514 and remained above 5200 for the rest of the phase (Fig. 2A). The number of active monitors reached a maximum of 449 in 2001, and the number of records per monitor per year peaked in 2004 at 16. This difference indicated that the average monitor sampled more frequently or intensively (more months or sites) during this 3-year period; however, results were affected by a relatively small number of "megamonitors" who were particularly active during this time. For example, from 2002 through 2004, 7 volunteers submitted from 100 to 380 data records per year. The percentage of certified volunteers who submitted data in phase II $(24 \%)$ was slightly lower than that in phase I.

The number of active groups crested at 95 in 2002 (Fig. 2B). From phase I to phase II, the average number of new groups per year dropped from 21 to 16 , while the average number of dropout groups per year rose from 8 to 19 (Table 2). By the end of phase II, the number of active groups $(\mathrm{n}=81)$ had decreased to about the level at the end of phase I (1998); however, the number of data records per monitor had risen by nearly $80 \%$. This indicated a decline in numbers of volunteers who were initially involved with AWW but monitored intermittently and gradually discontinued.

Phase II primary funding averaged $\$ 200,000$ per year (Fig. 2C). Peak funding for the program occurred in 2002, and this coincided with peak staff time (7.2 FTEs) and maximum volunteer time from monitors (22,510 hours). Financial support to AWW from AU began in 2000 to cover the program director's salary, allowing greater allocation of grants for staff time to meet program needs.

One of the most important activities during this period was the development of a database that monitors could use to enter and analyze their data online. The original, spreadsheet-type database used from program inception into the early 2000s became increasingly cumbersome and time-consuming to use as program complexity and the amount of data increased. It became difficult to respond to summarized data requests from monitors and agencies, track the status of certifications, and implement the quality assurance plan.

By 2003, an MS Access relational database was developed that had components for AWW office and public use. The AWW office component of the database, not available to the public, documents such things as group, monitor, and trainer contact information; site locations; and certifications. The public component allows online access to the water data and gives monitors options for data entry and custom analyses. These two databases are quality assured on a regular basis, and their integration greatly facilitated the tracking of key program indicators (Table 2) for improved program management. The online database was quickly adopted by monitors, and data submission reached $52 \%$ by the end of phase II.

\section{Phase III: precarious equilibrium, 2005-2010}

Phase III was characterized as having relatively stable monitoring effort and group participation compared with previous phases. The number of active monitors ranged from 322 to 350 (Fig. 2A), and the number of data records varied from 4200 to 4552 (less than $8 \%$ ). Records per monitor averaged 13 per year. Both the number of monitors and records submitted were virtually identical at the beginning and end of this phase (Fig. 2A), indicating that an equilibrium was reached in these aspects of program development. The rate at which certified volunteers became active monitors rose slightly to $27 \%$, but overall was remarkably stable throughout the study (Table 2). Online data submission by monitors averaged $88 \%$ in this phase.

An average of 73 groups participated each year in this phase. About 7 new groups became active and 12 groups became inactive per year (Table 2), resulting in a net loss of active groups (Fig. 2B). The characteristics of AWW groups were analyzed in early phase III (Deutsch et al. 2009) and again for this study. Results of the two analyses were similar, with stream groups making up more than $70 \%$ of the total.

Funding remained relatively stable and averaged $\$ 145,000$, but staff time dropped from about 5 to 3 FTEs during this period (Fig. 2C). The decline in staff was partly because of the increased costs of personnel and operations, and partly because of the necessity of staff to work part-time on other projects. By 2010 , staff time was less than 50\% the maximum that occurred in 2002. Volunteer hours declined by about $15 \%$ through phase III.

\section{Phase IV: new era? 2011-2013}

The grant that primarily supported the AWW program for 19 years was discontinued after 2010, attributed to severe budget cuts to ADEM from the Alabama legislature and cuts to the grants program from EPA. With this abrupt loss in funding, AWW was confronted with the challenge of quickly securing enough resources to keep the program viable, while addressing the challenges of monitor participation that long-term program trends revealed. The remaining EPA grant funds were conserved and extended through the early part of phase IV, but staff time and services to monitors had to be cut. Staff FTEs reached their lowest level of 2.9, almost half of that in phase II when funding peaked (Table 2), and travel for face-to-face meetings was reduced.

In 2012, AWW negotiated a new institutional arrangement at AU that resulted in moving from the School of Fisheries, Aquaculture and Aquatic Sciences to the Water Resources Center and receiving increased financial support from the Alabama Agricultural Experiment Station and Alabama Cooperative Extension System for staff salaries. Since 2013, increased FTEs allowed for greater interactions with monitors, but the operational budget for travel, communications, and supplies remained relatively low and dependent on external funds that have been difficult to secure.

One of the most important and difficult changes in this phase was the discontinuation of offering free chemical reagents and test kit supplies to active monitors, a service that supported volunteers since the program began. Some monitors expressed disappointment and frustration about these changes, and it became uncertain if they would continue with AWW. The number of groups dropping out rose from 6 in 2011 to 12 in 2013 (Fig. 
Table 3. Impacts of Alabama Water Watch (AWW) on ecosystems and society.

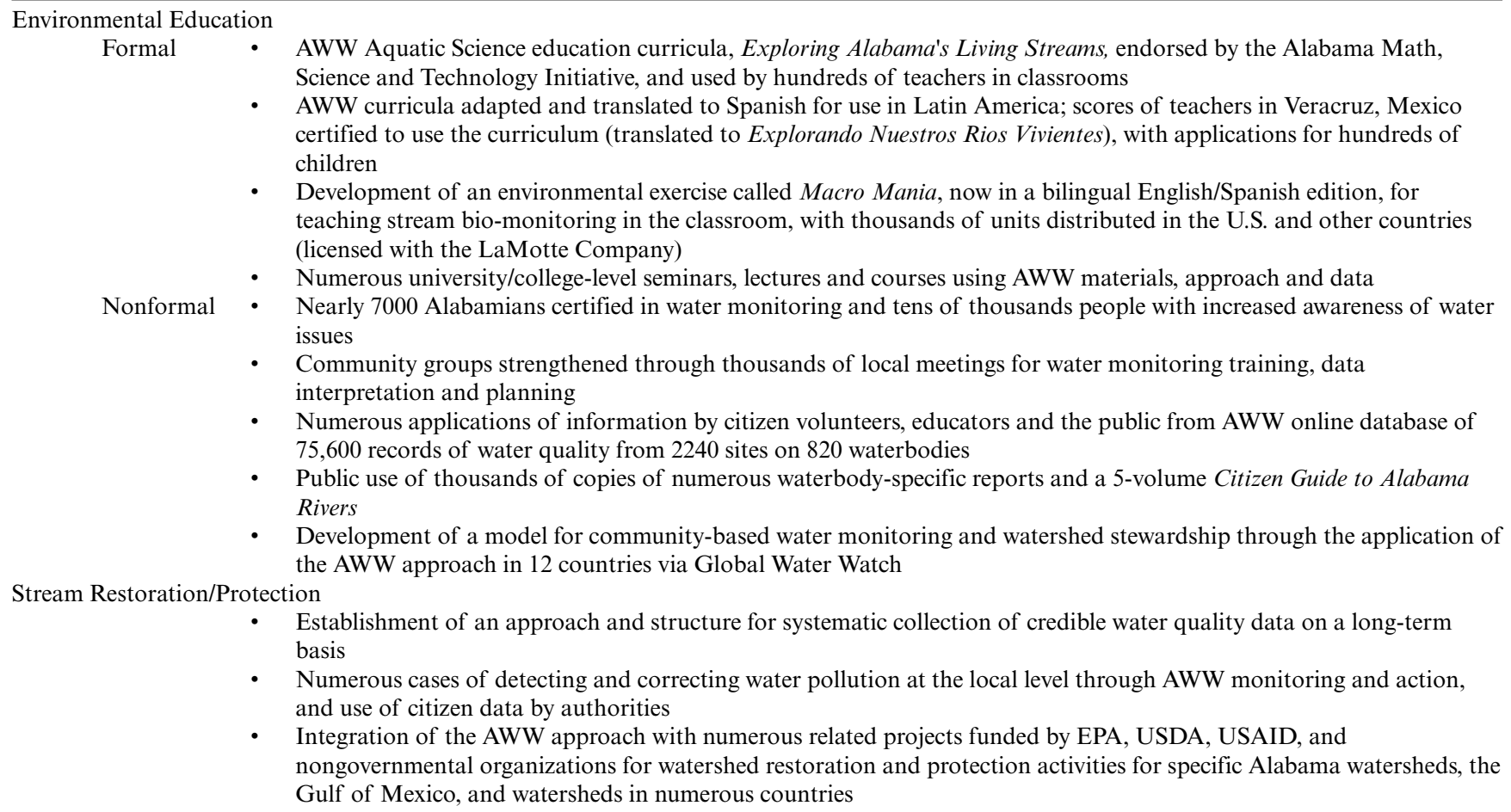

- AWW curricula adapted and translated to Spanish for use in Latin America; scores of teachers in Veracruz, Mexico certified to use the curriculum (translated to Explorando Nuestros Rios Vivientes), with applications for hundreds of children

- Development of an environmental exercise called Macro Mania, now in a bilingual English/Spanish edition, for teaching stream bio-monitoring in the classroom, with thousands of units distributed in the U.S. and other countries (licensed with the LaMotte Company)

- Numerous university/college-level seminars, lectures and courses using AWW materials, approach and data

Nonformal - Nearly 7000 Alabamians certified in water monitoring and tens of thousands people with increased awareness of water issues

- Community groups strengthened through thousands of local meetings for water monitoring training, data interpretation and planning

- Numerous applications of information by citizen volunteers, educators and the public from AWW online database of 75,600 records of water quality from 2240 sites on 820 waterbodies

- Public use of thousands of copies of numerous waterbody-specific reports and a 5-volume Citizen Guide to Alabama Rivers

- Development of a model for community-based water monitoring and watershed stewardship through the application of the AWW approach in 12 countries via Global Water Watch

Stream Restoration/Protection

- Establishment of an approach and structure for systematic collection of credible water quality data on a long-term basis

- Numerous cases of detecting and correcting water pollution at the local level through AWW monitoring and action, and use of citizen data by authorities

- Integration of the AWW approach with numerous related projects funded by EPA, USDA, USAID, and nongovernmental organizations for watershed restoration and protection activities for specific Alabama watersheds, the Gulf of Mexico, and watersheds in numerous countries

Water Policy

- Integration of citizen volunteer data into Triennial Reviews of water quality and Reports to Congress by the Alabama Department of Environmental Management

- $\quad$ AWW data used for revisions of Impaired Stream Lists (303d Lists) and development of Total Maximum Daily Loads (TMDLs) by ADEM and EPA

- AWW data used, in part, to achieve Outstanding Alabama Water use-classification for Wolf Bay and the Magnolia River, and Treasured Alabama Lake designation for Lake Martin by ADEM

- Numerous impacts on natural resource planning and policy in other countries via GWW efforts

2B), suggesting that the lack of free monitoring supplies had a negative effect on group participation.

In spite of funding challenges, the first three years of phase IV had several program indicators that were similar to phase III. The number of workshops conducted, records per monitor, new groups formed, active groups, and active sites remained relatively unchanged (Table 2, Fig. 2). Online data submission by monitors reached a peak of $92 \%$ in this phase.

\section{Impacts on ecosystems and society}

Throughout the development of AWW, there have been significant positive impacts on Alabama's ecosystems and society (Table 3). These may generally be categorized into environmental education, restoration/protection of waterbodies, and advocacy for improved water policy (Deutsch et al. 2007, Deutsch 2013).

\section{Environmental education}

In the AWW context, environmental education is the use of the monitoring approach, citizen data, and other activities to raise community awareness and appreciation of water resources. Many schools have integrated AWW monitoring within classroom exercises or extracurricular activities, and educational groups have made up about one-third of all AWW groups. These schools have used AWW techniques to win several local, state, and regional awards, including the Best Environmental Education Project, awarded annually by the Environmental Education Association of Alabama.

AWW developed a curriculum for grades 4-12 called Exploring Alabama's Living Streams, which was endorsed by the Alabama Math, Science, and Technology Initiative of the State Department of Education. Scores of teachers have attended training workshops on how to apply this in the classroom, and hundreds of students have benefited. The curriculum became an important way to link AWW monitoring groups with classrooms. Instead of teachers relying on AWW program staff to respond to requests for classroom visits and demonstrations, local experts go to the schools and share their monitoring experiences and related activities.

\section{Restoration and protection of waterbodies}

Many AWW groups have monitored several sites for 10 or more years, providing a quantity of data that often exceeds that of the state regulatory agency or other sources. A goal of AWW is to protect the good and restore the bad using monitoring data to pinpoint sources of problems and document positive remediation. 
After water data are submitted online by monitors and quality assured by AWW program staff, monitors and staff analyze conditions and trends of waterbodies and compare results with governmental standards. These analyses may be as simple as a monitor noting a site with low dissolved oxygen or high bacteria counts and notifying authorities, or as complex as data summaries from many sites over a long period conducted by program staff. Restoration activities may result from neighbor-to-neighbor persuasion that quickly stops pollution, or from a long process of engaging stakeholders to identify sources of pollution and develop a watershed management plan. ADEM has used AWW data to delist sites from the $303 \mathrm{~d}$ list (impaired streams), and it has funded two projects for 5-10 years to implement watershed management plans where AWW groups were strong and where AWW data revealed problems. Numerous other governmental agencies, private environmental consultants, and university researchers have requested AWW data for their work in waterbody protection and restoration.

\section{Advocacy for improved water policy}

The AWW model of community-based watershed stewardship (Deutsch et al. 2010; Global Water Watch, http://www. globalwaterwatch.org) suggests that when communities have intimate knowledge of a particular watershed by having conducted long-term monitoring, they have a unique and powerful way to advocate for positive change. AWW has helped citizen volunteers acquire the skills and credibility they need for collecting valid water data and meeting quality assurance standards that are recognized by governmental agencies and other users of the information.

Many policy successes of AWW monitors have taken several years to come to fruition. Notable examples have been the upgrades of many stream use classifications by environmental regulatory agencies, resulting in greater legal protection for a waterbody. AWW monitor testimonials at a public hearing conducted by ADEM were directly linked to the upgrade of more than a dozen sites to a Fish and Wildlife classification from a lower category. AWW volunteers on Wolf Bay and the Magnolia River were instrumental in getting their waterbodies classified as Outstanding Alabama Water, the highest level of protection offered by the state. The Lake Watch of Lake Martin citizen group was one of the first to participate in AWW and, after many years of effort, played an important role in getting their waterbody designated as the first Treasured Alabama Lake by executive order of the governor.

The positive impacts of AWW on Alabama's ecosystems and society are intertwined with those of many other organizations, and it is difficult to attribute high-level change to any particular group. Environmental organizations in Alabama that predate AWW include the Audubon Society in 1946, the Alabama Environmental Council in 1967, and the Cahaba River Society in 1988. Those that formed after AWW include the Alabama Rivers Alliance in 1998, the Alabama Clean Water Partnership in 1999, and several Rivekeepers of the Waterkeeper Alliance in 1999-2013. These organizations run the gamut of approaches, from the "neutral table" and broad partnerships of industry, business, and state agencies facilitated through the Clean Water Partnership to the activist approach of the Riverkeepers.

The unique niche of AWW remains the community-based and science-based promotion of volunteer water monitoring, with application of credible data for improved water quality and policy. Together, and in various degrees of collaboration, the work of the environmental community has largely affected the rise of the state's environmental ranking from \#50 in the early 1990s (Hall and Kerr 1991) to \#38 in 2010 (Sauter et al. 2010). Such progress underscores the findings of Mullen and Allison (1999), who stressed the importance of stakeholder involvement and social capital in Alabama.

\section{DISCUSSION}

The study revealed the importance of identifying key indicators of program viability and the effectiveness of using annual averages of indicators to do an assessment of a volunteer monitoring program. This simple approach is broadly applicable for other programs to emulate, although more sophisticated statistical analyses might reveal other important features of program trends.

AWW represents only one model of how citizen volunteer water monitoring programs are organized, and the unique mix of decisions about design and implementation (Table 1) set the program on a course that influenced volunteer participation, partnerships, and resilience to inevitable change. Study results and guided discussions among program personnel suggest that at least five interactive factors influenced how AWW evolved, and they represent the major challenges the program now faces.

\section{Saturation of potential groups}

The general decline in the number of new groups per year from phases I to III suggests a decrease in the potential for new groups. Within the first 10-15 years of AWW, most of the existing community groups that were focused on lakes and streams became aware of or participated in AWW. With the limited number of reservoirs to serve as focal sites for group formation, it might seem that the "market" for new groups would saturate.

In spite of some level of group saturation, there are many opportunities for program growth. Several Alabama reservoirs and streams are large enough for more than one AWW group to function. For example, one environmental group started monitoring on Lewis Smith Lake in north Alabama in 1997, but by 2010 , five groups around this large reservoir were monitoring. These groups did not compete, but pooled resources and participated in a larger-scale watershed management plan that attracted external funding that benefited all groups.

\section{Loss of monitors from aging}

Some of the strongest AWW groups are largely composed of retirement-age people who have discretionary time and money, and a strong vested interest in water quality (Deutsch et al. 2009). There has been a "graying" of AWW as these loyal monitors stayed with the program for 20 years, and now several original participants have discontinued for age-related reasons. Besides the initial cadre of older volunteers, new AWW recruits from reservoir and coastal groups tended to be at or near retirement age. In support of this observation was a distinct difference in age among AWW monitors who responded to surveys in 1995 (Droke 1996) and 2012 (ongoing AWW study, unpublished observation). In 1995, about 2 years after the program began, $62 \%$ of about 100 respondents were under 50 years old and none were over 70 . By 2012 , only $30 \%$ of about 300 respondents were under 50 and $14 \%$ were over 70 . This situation is common within voluntary and civic organizations nationwide, and Robinson (2006) described 
concerns among many environmental groups in Alabama that there are fewer young people to take over leadership positions.

It is difficult to implement youth-oriented and public awareness activities with a concurrent emphasis on rigorous collection of credible data. However, AWW now faces senescence and needs to shift its strategy toward youth. A Young Water Watch program is being initiated to attract young people and prepare them for becoming adult monitors. There have also been greater interactions with educators through an AWW-developed classroom curriculum. A new partnership between AWW and the Alabama Cooperative Extension 4-H program will give AWW access to thousands of youths and help to promote their awareness of water resources.

\section{Disillusionment and volunteer fatigue}

The process of stopping pollution, restoring degraded environments, and improving water policy is often long and arduous. Some AWW volunteers stopped monitoring after they either won or lost their short-term environmental goals. Others discontinued after years of monitoring because they became disillusioned with the difficulty of fighting government bureaucracy and corporate resistance.

Previous studies have shown that volunteer water monitoring groups typically last about three to seven years (Klang and Heiskary 2000, Nerbonne and Nelson 2004, Deutsch et al. 2009), indicating the difficulty in maintaining group motivation and solidarity. The AWW program has tried to address volunteer fatigue and dropout by more effectively communicating success stories with monitors and the general public. A greater effort has been made to disseminate these stories via user-friendly waterbody reports, internet blogs, newsletters, and face-to-face meetings with volunteer groups statewide. Group learning and helping the environment have been found to be key motivations for volunteers to participate in citizen science programs (Ryan et al. 2001).

\section{Societal changes}

Much has been written in recent years about the unfortunate trend of American youths to stay indoors more, becoming enamored with electronic devices and suffering from "nature deficit disorder" (Louv 2005). Also, some have described a decrease in a sense of civic duty and volunteerism (Volunteering in America, http://www.volunteeringinamerica.gov/AL). Programs like AWW may suffer from these trends in spite of the best efforts to implement high-quality activities.

To address this societal condition, AWW workshops are designed to be enjoyable and interactive, with nearly half of the time involving outdoor, hands-on activities. Workshops and other means of outreach continue to foster an appreciation for Alabama's water resources and unusually high aquatic biodiversity in an effort to engage the public in protecting these resources. A watershed exercise was developed that introduces the use of the many features of the AWW online database through entering, analyzing, and graphing simulated data. These skills can then be applied by AWW monitors for entering and analyzing their actual data. The program is also beginning to make greater use of short videos that demonstrate monitoring techniques or teach aspects of data applications.

\section{Funding}

Funding has been a constant challenge in virtually all monitoring programs (Green et al. 2013), and it seems to have limited the growth of AWW. The core government grant for AWW was unusually secure for nearly 20 years, but the decline in funding from 2002 through 2013 resulted in a reduction of AWW staff time that seems to have led to fewer volunteer hours. The correlation between AWW funding and monitor effort underscored the importance of face-to-face meetings and rapid response to the needs of volunteers. As much as strong volunteerbased programs would like to think that funding is relatively unimportant, several salaried personnel are almost always required to develop and maintain a statewide program.

From its inception, AWW attempted to diversify its funding and promote greater efficiencies in program implementation. Grants have been secured from related projects and AWWA that covered partial salaries of AWW staff. The reduction of staff time for AWW was compensated by improvement of the database and online tools, reducing the time required to process data. Also, volunteer trainers conducted an increasing number of the 70-80 workshops per year, greatly reducing staff needs while increasing the number of new monitors and groups.

\section{Keys to AWW sustainability}

The success of AWW in spite of the challenges discussed above suggests that six factors have been critical for program viability.

\section{Consistent attention to monitors}

AWW has been committed to meeting volunteers' needs by conducting workshops at the local level and being available for support after a person starts to monitor. A designated monitor coordinator and other AWW personnel regularly answer monitor questions, arrange for new workshops, and attend group meetings to help interpret water data and plan action steps.

\section{Credible data with quality assurance protocols}

AWW has consistently focused on data credibility and became one of the first statewide programs to acquire EPA approval on quality assurance plans for citizen volunteer water data. This achievement bolstered AWW's reputation and attracted a type of volunteer who is serious about using scientific information to manage and protect the environment. It also enhanced data use by governmental agencies and other professionals, which provided motivation for continued monitoring by volunteers.

Online database with analytical tools

A user-friendly online database created a cost-effective way for monitors to quickly enter and analyze their data. Database features increased the accuracy of water quality information by flagging unusual values and allowed for easy comparisons of citizen data with water quality standards. The office portion of the database enabled accurate tracking of monitors, sites, and volunteer trainers to meet quality assurance plan protocols and generate information about the program that improved its management.

\section{Volunteer trainers}

The process of becoming an AWW volunteer trainer is rigorous, requiring a certification workshop, internships with veteran trainers, and periodic recertification sessions. Nevertheless, scores of volunteers have become trainers and about 20-30 have been 
active each year. Volunteer trainers are spread throughout the state and are often more responsive to local needs for workshops, especially for small groups. This allows new volunteers to get certified and stay active without continually drawing on program staff and conserves program resources while increasing AWW group autonomy.

\section{Nongovernmental association}

As a legally incorporated and registered 501.c.3 organization, AWWA has been able to attract funding and advocate water policy in ways that are not possible for the university-based program. The AWWA Board has been largely composed of local group leaders and veteran monitors who have had continual input into the direction and activities of AWW, thus moving it toward a cocreated model of Public Participation in Scientific Research (Shirk et al. 2012). Relatively small but consistent grants to AWWA from foundations and other nongovernmental organizations have been used to finance volunteer trainer expenses, monitoring supplies, publications, and special events. AWWA has continually refined how it promotes AWW, especially following the discontinuation of the government grant, to increase membership, funding, and the influence of the citizen voice in water issues.

\section{Institutional transition for funding and staff continuity}

AWW was fortunate in having one of the longest series of EPA 319 Program grants in the nation. Consistent funding for 20 years was largely achieved by developing an effective, reputable program that met environmental regulatory agency (ADEM) goals at a time when federal budgets for the environment were relatively strong. AWW was able to transition through the discontinuation of these grants, in large part, by moving to a new institutional home within a land grant university. This resulted in a stronger commitment to the AWW mission and increased salary support for AWW staff.

From 2002 through 2010, when funding cuts resulted in staff time decreases of $50 \%$, average annual volunteer hours and data records declined by only $33 \%$ and $23 \%$, respectively. Even in the three years since the core government grant was discontinued (phase IV), indicators of AWW success have remained relatively stable (Fig. 2). This suggests that AWW has achieved a resiliency that is based on the social, technical, and institutional factors listed above.

\section{Organizational development}

After more than 20 years of development, AWW has reached a precarious point shared by many volunteer programs nationwide, but one with opportunities. The primary challenge is to continue building a strong, science-based monitoring program while simultaneously appealing to younger audiences and facing an abrupt loss of a government grant for operational funding.

It is typical for organizations like AWW to go through cycles of growth and decline, and the pattern of AWW indictors is similar to that of other programs and businesses that promote a new product or idea (Whetten 1987). Nonprofit organizations that introduce a relevant service to the public often experience initial, enthusiastic support and strong growth (e.g., AWW phase I), followed by a period of mild decline and stabilization (phases IIIII). As organizations reach this stage of maturity, they need fresh ideas and new strategies or they usually experience steady, sometimes dramatic, decline. It is challenging for programs like AWW to implement strong activities in monitoring, education, restoration, and advocacy, so important choices are needed in how to prioritize a variety of program components.

Whetten (1987) noted that a decline in some areas does not necessarily mean organizational death, but can stimulate renewal. AWW is actively seeking a revised model of operations that builds on two decades of partnerships and accomplishments. Some AWW monitors and supporters believe that, although initially difficult, the loss of funding from the state environmental regulatory agency gives AWW a chance to strengthen as a grassroots organization with less governmental intervention. Also, funding cuts to state environmental agencies might ironically strengthen volunteer programs like AWW because of the continued need for monitoring data and the commitment of government to stakeholder input for watershed management (Lawrence and Deagan 2001, Conrad and Daoust 2008).

The nearly 70 community groups that currently participate in AWW are semiautonomous because the program has fostered a high level of citizen empowerment and participation for more than 20 years. This approach created a significant buffer against collapse from a sudden loss of funding and enabled AWW to adjust to threats to its viability. The sustained volunteer effort, increased university support, and alternative external funding has resulted in cautious optimism that AWW will be able to adequately respond to its many challenges and enter a new phase of growth and positive impacts for Alabama.

Responses to this article can be read online at: http://www.ecologyandsociety.org/issues/responses. $\mathrm{php} / 7578$

\section{Acknowledgments:}

The authors thank coworkers Eric Reutebuch, Mona Dominguez, and Rita Grub for assistance with program trend analyses and continued camaraderie in AWW. Thanks to A. Scott Hughes, Norman Blakey, and Patti Hurley for long-standing support for AWW from ADEM, and to Drs. Sam Fowler, William Batchelor, and Paul Brown of Auburn University for their roles in transitioning $A W W$ to the $A U$ Water Resources Center with staff salary support. Nearly 7000 Alabamians have participated in $A W W$ workshops and thousands of them became volunteer water monitors. They have changed how Alabama thinks about water issues, and their efforts are gratefully acknowledged. Water monitors in the Global Water Watch program in several countries have partnered with $A W W$ for mutual learning, joint funding, and improvements in watershed stewardship.

\section{LITERATURE CITED}

Bonney, R., H. Ballard, R. Jordan, E. McCallie, T. Phillips, J. Shirk, and C. C. Wilderman. 2009. Public participation in scientific research: defining the field and assessing its potential for informal science education. A Center for Advancement of Informal Science Education (CAISE) Inquiry Group Report. CAISE, Washington, D.C., USA. 
Conrad, C. C., and K. G. Hilchey. 2011. A review of citizen science and community-based environmental monitoring: issues and opportunities. Environmental Monitoring and Assessment 176:273-291. http://dx.doi.org/10.1007/s10661-010-1582-5

Conrad, C. T., and T. Daoust. 2008. Community-based monitoring frameworks: increasing the effectiveness of environmental stewardship. Environmental Management 41:356-358. http://dx.doi.org/10.1007/s00267-007-9042-x

Deutsch, W., L. Lhotka, and S. S. Ruiz-Córdova. 2009. Group dynamics and resource availability of a long-term volunteer water-monitoring program. Society \& Natural Resources 22:637-649. http://dx.doi.org/10.1080/08941920802078216

Deutsch, W. G. 2013. Alabama Water Watch and Global Water Watch: models of community-based watershed stewardship. Pages 256-263 in in B. G. Lockaby, editor. Auburn speaks: on water. Auburn University, Auburn, Alabama, USA.

Deutsch, W. G., E. Reutebuch, and S. S. Ruiz-Córdova. 2007. Validity and applications of citizen volunteer water-quality data: a case from Alabama. Water Resources Impact 9(5):16-20.

Deutsch, W. G., S. S. Ruiz-Córdova, and B.L. Duncan, editors. 2010. Community-based water monitoring, a practical model for global watershed stewardship. Auburn University, Auburn, Alabama, USA.

Droke, J. L. 1996. An analysis of the Alabama Water Watch program from the resource mobilization perspective. Thesis. Auburn University, Auburn, Alabama, USA.

Green, L., K. Stepenuk, E. Herron, W. Deutsch, and A. Sigler. 2013. Assessing the needs of volunteer water monitoring programs: survey results and implications. Extension Volunteer Monitoring Network. National Water Program, Washington, D.C., USA. [online] URL: http://www.usawaterquality.org/volunteer/pdf/ NationwideInquiry/NeedsAssessmentFinal.pdf

Hall, B., and M. Kerr. 1991. The 1991-1992 green index: a stateby-state guide to the nation's environmental health. Island Press, Washington, D.C., USA.

Kerr, M., E. Ely, V. Lee, and A. Mayio. 1994. A profile of volunteer environmental monitoring: national survey results. Lake and Reservoir Management 9:1-4. http://dx.doi.org/10.1080/0743814$\underline{9409354713}$

Klang, J. L. K., and S. Heiskary. 2000. Minnesota methods for analyzing, applying and disseminating volunteer lake monitoring data. Paper presented at the National Water Quality Monitoring Council National Monitoring Conference, 26-29 April. Austin, Texas, USA.

Lawrence, R. L., and D. A. Deagan. 2001. Choosing public participation methods for natural resources: a context-specific guide. Society \& Natural Resources 14:857-852. http://dx.doi. org/10.1080/089419201753242779

Louv, R. 2005. Last child in the woods: saving our children from nature deficit disorder. Algonquin Books, Chapel Hill, North Carolina, USA.

Mullen, W. M., and B. E. Allison. 1999. Stakeholder involvement and social capital: keys to watershed management success in
Alabama. Journal of the American Water Resources Association 35(3):655-662. http://dx.doi.org/10.1111/j.1752-1688.1999.tb03621. $\underline{\mathrm{X}}$

Nerbonne, J. F., and K. C. Nelson. 2004. Volunteer macroinvertebrate monitoring in the United States: resource mobilization and comparative structures. Society \& Natural Resources 17(9):817-839. http://dx.doi.org/10.1080/08941920490493837

Robinson, L. J. 2006. Information exchange among environmental groups in Alabama and Romania. Dissertation. Auburn University, Auburn, Alabama, USA.

Ryan, R. L., R. Kaplan, and R. E. Grese. 2001. Predicting volunteer commitment in environmental stewardship programmes. Journal of Environmental Planning and Management 44 (5):629-648. http://dx.doi.org/10.1080/09640560120079948

Sauter, M. B., C. B. Stockdale, D. A. McIntyre, and A. C. Allen. 2010. The environmental state of the union: a survey of pollution, energy use and policy in all 50 states. 24/7 Wall St., 16 December. [online] URL: http://247wallst.com/2010/12/16/the-environmentalstate-of-the-union-a-survey-of-pollution-energy-use-and-policyin-all-50-states/

Savan, B., A. J. Morgan, and C. Gore. 2003. Volunteer environmental monitoring and the role of the universities: the case of citizens' environment watch. Environmental Management 31(5):561-568. http://dx.doi.org/10.1007/s00267-002-2897-y

Shirk, J. L., H. L. Ballard, C. C. Wilderman, T. Phillips, A. Wiggins, R. Jordan, E. McCallie, M. Minarchek, B. V. Lewenstein, M. E. Krasny, and R. Bonney. 2012. Public participation in scientific research: a framework for deliberate design. Ecology and Society 17(2): 29. http://dx.doi.org/10.5751/ ES-04705-170229

U.S. Census Bureau, Population Division. 2013. Annual estimates of the resident population: April 1, 2010 to July 1, 2012. U.S. Census Bureau, Washington, D.C., USA. [online] URL: http://factfinder. census.gov/faces/nav/jsf/pages/index.xhtml

Wagenet, L. P., and M. J. Pfeffer. 2007. The social context of volunteer environmental monitoring. Water Resources Impact 9 (5):6-8.

Whetten, D. A. 1987. Organizational growth and decline processes. Annual Review Sociology 13:335-358. http://dx.doi. org/10.1146/annurev.so.13.080187.002003 